
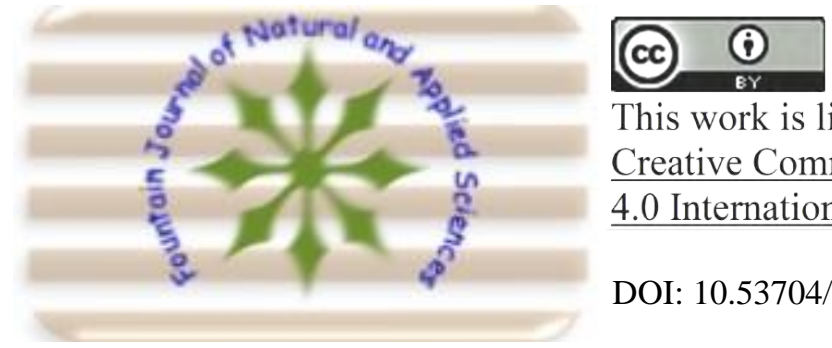

This work is licensed under Creative Commons Attribution 4.0 International License.

DOI: 10.53704/fujnas.v6i2.149

A publication of College of Natural and Applied Sciences, Fountain University, Osogbo, Nigeria.

Journal homepage: www. fountainjournals.com

ISSN: 2354-337X(Online),2350-1863(Print)

\title{
Antibiotic Susceptibility Patterns of Pseudomonas Species Isolated From Clinical and Environmental Samples in Awba Dam, Ibadan
}

\author{
${ }^{1}$ Senbadejo, T.Y. and ${ }^{2}$ Fagade, O.E. \\ ${ }^{1}$ Department of Biological Sciences, College of Natural and Applied Sciences, Fountain University Osogbo, Osun, Nigeria. \\ ${ }^{2}$ Department of Microbiology, Faculty of Science, University of Ibadan, Ibadan, Nigeria.
}

\begin{abstract}
Pseudomonas species are common pathogenic Gram negative bacteria frequently found in both environmental and clinical samples. They are opportunistic pathogen and could be multidrug resistant (MDR); their presence in the environment signifies threat to the public health. Water from Awba dam is used as municipal water supply for drinking, fishing and agricultural purposes in the University of Ibadan which gives reason for proper monitoring. The study was designed to isolate and characterize Pseudomonas species present in Awba dam reservoir and also to compare its antimicrobial resistance pattern with clinical isolates. Pseudomonas was isolated using Centrimide agar (Oxoid) and identification was done to species level using classical method. Disk diffusion method was applied to test antibiotic sensitivity according to clinical and laboratory standard guidelines. A total of 200 bacteria isolates were obtained from water and sediment, of which 30 were found positive for Pseudomonas giving a prevalence of 15.0\% (30/200). Eighteen clinical samples were collected from University College Hospital with about 50\% from urine, 27.8\% (Ear), $11.1 \%$ (wound) and $5.6 \%$ each from pleural effusion and nasopharyngeal tube. Two species of Pseudomonas; aeruginosa and fluorescens were identified. Out of the 10 antibiotics used, environmental isolates showed no resistance to gentamicin, amikacin, ciprofloxacin, tetracycline and imipinem while clinical isolates showed 83.3,16.7, 83.3, 100 and $11.1 \%$ resistance to the antibiotics respectively. Amikacin and Imipinem was the most effective drug for both environmental and clinical Pseudomonas isolates. High rates of MDR Pseudomonas (94.4\%) from clinical strains and $13.3 \%$ of the environmental strains were observed. In conclusion, the result shows that Pseudomonas isolates from the clinical specimens are more exposed to antibiotics, and MDR isolates in the water system can be transferred to humans and animals.
\end{abstract}

Keywords: Antibiotic resistance, water, multidrug resistance (MDR), Pseudomonas aeruginosa, Pseudomonas fluorescens

\section{Introduction}

Pseudomonads are a large group of free living bacteria that live primarily in soil, seawater, and fresh water. Pseudomonas is the most common

genera in crustaceans, marine fish and bivalves

${ }^{\star}$ Corresponding author: +2348058109442

Email address: tosinoble@yahoo.com 
(Alexopoulos et al., 2011). Pseudomonas is one of the most common gram negative pathogenic bacteria, frequently found in different environmental samples such as soil, sediments. Pseudomonas species have been incriminated in a number of waterborne outbreaks including those associated with use of recreational waters (Mena and Gerba, 2009); showers, hot tubs and swimming pools (Pirnay et al., 2005); thus making the pathogens of growing public health concern.

$P$. aeruginosa is an opportunistic pathogen amongst the Pseudomonads that is most commonly associated with many infectious diseases seen in humans (Silby et al., 2011). They are often associated with infections of the urinary tract, respiratory system, soft tissue, bone and joint, gastrointestinal infections, dermatitis, bacteremia, and a variety of systemic infections, particularly in patients with severe burns, cancer and AIDS (Pirnay et al., 2005). These bacteria are widely distributed in nature and can survive on a wide variety of surfaces as it found its entry into the hospital environment either through visitors and patients or goods that enter in hospital. Contact transmission or vehicle transmission is common mode of transmission in hospital (Todar, 2011; Murray et al., 2002). P. aeruginosa is an opportunistic nosocomial pathogen that resists several antimicrobial agents (Brooks et al., 2011; Meenakumari et al., 2011). A major factor in its importance as a pathogen is its intrinsic resistance to antibiotics and disinfectants (Campisano et al., 2008). They represent a threat to public health because of their status as multidrug resistant bacteria. Multidrug-resistant (MDR) P. aeruginosa phenotype are known as those that are resistant to one antimicrobial agents in three or more anti-pseudomonal anti-microbial classes (carbapenems, fluoroquinolones, penicillins/cephalosporins and aminoglycosides) as stated by Centre for Disease Control and Prevention (CDC) (Magiorakos, 2011). Pseudomonas is one of the most common pathogenic bacteria, frequently found in different environmental samples. Their presence in water also poses the risk of transferring resistance to other pathogenic bacteria present in the human body (Mavridou et al.,
1994). Pseudomonas aeruginosa is an emerging opportunistic pathogen in healthcare settings and is amongst the leading causes of nosocomial pneumonia associated with high mortality rates (Rossolini and Mantengoli, 2005). Many of the antibiotic resistance bacteria that have been detected are of clinical origin i.e. hospital settings, environmental isolates have recently been implicated in many cases of antibiotic resistance. Water from Awba dam is used in municipal water supply for drinking, fishing and agricultural purposes. It experiences human inputs of complex mixture of domestic effluents from halls of residences in the University of Ibadan which could exert more selective pressure on bacteria populations in Awba stream and Reservoir. Therefore, there is need to study the antimicrobial resistance pattern present in Awba Dam to determine the level of resistance of the species to different classes of antibiotics determining multiple antibiotic resistance (MAR) index and compare with that of clinical isolates.

\section{Materials and Methods Sample Collection}

Water was collected aseptically in sterile glass bottles from different sampling points by directly dipping the bottles into the surface of the water by means of canoe. The collection was done at different station points from one end to the other in each sampling station. Each sample $A$ and $B$ were made up of composite samples from the three stations. The samples were labelled properly and transported on ice to the laboratory for analysis.

Sediments collection was also made up of composite samples from three different stations. Samples were collected using a Van Veen grab sampler by means of canoe, emptied into pre-labelled polythene bags and taken to the laboratory for sorting and analysis.

\section{Statistical analysis}

Relevant data were collectively documented using Microsoft Excel data analysis tool. Values were expressed in means and percentage.

\section{Results}

A total of two hundred bacteria isolates were obtained from water and sediment. Among the total 
samples, 30 isolates were identified as Pseudomonas giving a prevalence of $15.0 \%$ (30/200). Out of the 30 , $11(36.6 \%)$ were isolated from sediment and 19 $(63.3 \%)$ from water (Table 1). Eighteen clinical samples were collected from University College Hospital with about 50\% from urine, 27.8 (Ear), 11.1\% (wound) and $5.6 \%$ each from pleural effusion and nasopharyngeal tube. The distribution is shown in Table 2.

Table 3 showed different Pseudomonas species isolated from both clinical and environmental samples. The results showed more Pseudomonas fluorescens than aeruginosa in sediment than water for environmental samples ( $80 \%$ and $20 \%$, respectively) while clinical samples showed more Pseudomonas aeruginosa than fluorescens $(55.5 \%$ and $44.4 \%$, respectively). The susceptibility tests of Pseudomonas species against 10 different antibiotics is de ss shown in Table 4. Results showed that all environmental isolates showed no resistance to gentamicin, amikacin, ciprofloxacin, tetracycline and imipinem while clinical isolates showed 83.3, 16.7, 83.3, 100 and $11.1 \%$ resistance to the antibiotics respectively. Also, environmental isolates were highly susceptible to ceftazidime, ofloxacin, cefepime, ticarcillin and chloramphenicol in the following order: 93.3, 86.7, 70.0, 60.0 and 26.7 while the highest sensitivity observed from clinical isolates was $33.9 \%$ to ticarcillin. Results showed that isolates from the clinical specimens were more resistant to antibiotics than those obtained from Awba dam. Table 5 shows percentage of isolates that were able to resist more than three antibiotics. $13.3 \%$ of the environmental strains and $94.4 \%$ of the clinical strains showed multiple antibiotic resistance.

Table 1: Frequency of Psedomonas isolates in water and sediment of Awba Dam

\begin{tabular}{lcc}
\hline Sample type & No & $\%$ \\
\hline Water & 19 & 63.3 \\
Sediment & 11 & 36.6 \\
\hline Total & 30 & 100 \\
\hline
\end{tabular}

Table 2: Distribution of Pseudomonas isolates among the patients specimens

\begin{tabular}{lll}
\hline Source/Site & $\begin{array}{l}\text { No } \\
\text { Isolates }\end{array}$ & of $\%$ \\
\hline Urine & 9 & 50 \\
Ear & 5 & 27.8 \\
Wound & 2 & 11.1 \\
$\begin{array}{l}\text { Pleural Effusion } \\
\text { Nasopharyngeal }\end{array}$ & 1 & 5.6 \\
tube & 1 & 5.6 \\
\hline TOTAL & 18 & 100 \\
\hline
\end{tabular}

Table 3. Pseudomonas aeruginosa and fluorescens isolated from environment and clinical samples

\begin{tabular}{lccc}
\hline Source/Site & $\begin{array}{c}\text { No of } \\
\text { isolates }\end{array}$ & $\begin{array}{c}\text { Pseudomonas } \\
\text { aeruginosa } \\
\text { No }(\%)\end{array}$ & $\begin{array}{c}\text { Pseudomonas } \\
\text { fluorescens } \\
(\mathrm{No} / \%)\end{array}$ \\
\hline Environment & 30 & $6(20)$ & $24(80)$ \\
\hline Clinic & 18 & $10(55.5)$ & $8(44.4)$ \\
\hline
\end{tabular}

Table 4: Antibiotics resistance patterns of Pseudomonas Isolates

\begin{tabular}{|c|c|c|}
\hline ANTIBIOTIC & $\begin{array}{l}\text { CLINICAL } \\
\text { ISOLATES } \\
(18) \\
\text { RESISTANT } \\
\text { NO }(\%)\end{array}$ & $\begin{array}{l}\text { ENVIRONMENTAL } \\
\text { ISOLATES (30) } \\
\text { RESISTANT } \\
\text { NO }(\%)\end{array}$ \\
\hline GENTAMICIN & $15(83.3)$ & $0(0.0)$ \\
\hline AMIKACIN & $3(16.7)$ & $0(0.0)$ \\
\hline CIPROFLOXACIN & $15(83.3)$ & $0(0.0)$ \\
\hline OFLOXACIN & $15(83.3)$ & $2(6.6)$ \\
\hline CEFTAZIDIME & $18(100)$ & $2(6.6)$ \\
\hline CEFEPIME & $15(83.3)$ & $4(13.3)$ \\
\hline TICARCILLIN & $12(66.7)$ & $11(36.6)$ \\
\hline TETRACYCLINE & $18(100)$ & $0(0.0)$ \\
\hline IMIPINEM & $2(11.1)$ & $0(0.0)$ \\
\hline CHLORAMPHENICOL & $15(83.3)$ & $20(66.6)$ \\
\hline
\end{tabular}


Table 5: Multiple antibiotic resistance (MAR) pattern of different Pseudomonas species isolated from Awba Dam samples

\begin{tabular}{lcccccccc}
\hline Type of Specimen & \multicolumn{2}{l}{$\begin{array}{l}\text { Pseudomonas } \\
\text { aeruginosa }\end{array}$} & MAR & \multicolumn{3}{c}{$\begin{array}{l}\text { Pseudomonas } \\
\text { fluorescens }\end{array}$} \\
\hline & NO & $\%$ & NO & $\%$ & NO & $\%$ & NO & $\%$ \\
WATER & 6 & 100 & - & - & 13 & 54.2 & 2 & 15.4 \\
SEDIMENT & - & - & - & - & 11 & 45.8 & 2 & 18.2 \\
TOTAL & $6 / 30$ & 100 & - & - & $24 / 30$ & 100 & $4 / 24$ & 16.7 \\
\hline
\end{tabular}

Table 6: Multiple antibiotic resistance (MAR) pattern of different Pseudomonas species isolated from Clinical samples

\begin{tabular}{|c|c|c|c|c|c|c|c|c|}
\hline \multirow[t]{2}{*}{ CLINICAL SOURCE } & \multicolumn{2}{|c|}{$\begin{array}{l}\text { Pseudomonas } \\
\text { aeruginosa }\end{array}$} & \multicolumn{2}{|c|}{ MAR } & \multicolumn{2}{|c|}{$\begin{array}{l}\text { Pseudomonas } \\
\text { fluorescens }\end{array}$} & \multicolumn{2}{|l|}{ MAR } \\
\hline & No & $\%$ & NO & $\%$ & NO & $\%$ & NO & $\%$ \\
\hline URINE & 7 & 70 & 7 & 100 & 2 & 25 & 1 & 50 \\
\hline EAR & 1 & 100 & 1 & 100 & 4 & 50 & 4 & 100 \\
\hline WOUND & 1 & 100 & 1 & 100 & 1 & 100 & 1 & 100 \\
\hline PLEURAL EFFUSION & - & - & & & 1 & 100 & 1 & 100 \\
\hline $\begin{array}{l}\text { NASOPHARYNGEAL } \\
\text { TUBE }\end{array}$ & 1 & 100 & 1 & 100 & - & 100 & - & - \\
\hline TOTAL & 10 & & $10 / 1$ & 100 & 8 & & $7 / 8$ & 87.5 \\
\hline
\end{tabular}

\section{Discussion}

In the present study, more than 200 bacteria were isolated from water and sediment samples obtained from different points of Awba Dam. Among them 30 samples were found to be positive for Pseudomonas species with about six of them as $P$. aeruginosa and the remaining as $P$. fluorescens. The isolation rate of $P$. aeruginosa in water $(20 \%)$ and $80 \%$ of $P$. fluorescens in water and sediment was observed. All Pseudomonas species were subjected to ten antimicrobial agents which are (penicillins) ticarcillin; (carbapenem) imipenem; (cephems) ceftazidime, cefepime; (aminoglycosides) gentamicin, amikacin; (quinolones) ciprofloxacin, ofloxacin; (phenicols), chloramphenicol; and tetracycline. The reason for choosing this antimicrobial was their wide use in the hospital as antipseudomonal agents. The studies on the antibiotic sensitivity of environmental isolates of Pseudomonas species are very scanty in literature. So the present study was carried out to find out the proportion of the resistance isolates in Awba dam and to compare their antibiotic resistance pattern with that of clinical samples. Pseudomonas is one of the major pathogens in healthcare associated infections (HAI) (Olayinka et al., 2009). This is not only because they cause infections that are associated with significant morbidity and mortality but also because of their increasing rates of resistance which make them more difficult to be treated with inexpensive antibiotics. Emerging and increasing resistance to newer and otherwise efficacious antibiotics may compound the whole problem (Okeke and Sosa, 2003). P. aeruginosa isolated from water were susceptible to all 
antibiotics while $P$. fluorescens in both water and sediment were resistant to one or more antibiotics used in the study. Among the ten antibiotics, complete sensitivity was found with imipenem and amikacin in environmental isolates. This is in consonance with the studies of (Marufa et al., 2015) who found complete sensitivity with imipenem in Pseudomonas aeruginosa isolated from surface water. Isolates from environmental samples (Water and Sediment) demonstrated high level of susceptibility to imipenem $30(100 \%)$, gentamicin 30 $(100 \%)$, amikacin 29 (96.7\%) and ciprofloxacin 29 $(96.7 \%)$ and Amikacin 15 (83.3\%), Imipenem 16 $(88.9 \%)$ for clinical isolates. This finding is consistent with that of other studies which reported high level of resistance for the fluoroquinolones (ciprofloxacin) and aminoglycosides (amikacin and gentamicin) respectively (Olayinka et al., 2004; Olayinka et al., 2009; Oduyebo et al., 1997).

The observation is contrary to a previous report suggesting that fluoroquinolones have lost their effectiveness against $P$. aeruginosa strains due to resistance (Jalal and Wretlind, 1998). Also in agreement with the observation in this study, NavonVenezia et al., 2005 reported considerable Pseudomonas resistance to the aminoglycosides (including gentamicin) and fluoroquinolones (including ofloxacin) in clinical isolates; while Lateef, 2004 observed high resistance to both antibiotics in Pseudomonas strains isolated from pharmaceutical effluents. The observations were not surprising as clinical environments tend to exert more selective pressure (leading to antibiotic resistance) on bacterial populations than non-clinical/nonpharmaceutical (e.g., municipal effluent) environments (Iwane et al., 2001; Schwartz et al., 2003). However the difference in resistance rates in these works may be explained by the increasing trend that had been noted globally (Okeke and Sosa, 2003). This may have implications on the effectiveness of the local and probably national hospital infection and antibiotic resistance control programs.

\section{Conclusion}

Human inputs of complex mixture of domestic effluents from halls of residences and other sources in the University of Ibadan should be reduced in order to reduce the number of bacteria population present in the dam.

The development of resistance to antimicrobials is a natural process, which cannot be stopped. Resistance means that people cannot be successfully treated and they remain ill for longer period of time. Also, epidemics are prolonged because of resistance and thus that there is a greater risk of infection to others. Results indicate that the resistance of Pseudomonas species in water may be caused by the uncontrolled disposal of effluents that may contain chemicals and antibiotic in the environment. Proper implementation of antibiotic policies and guideline must be there in every hospital to local susceptibility pattern. This study demonstrated that MAR Pseudomonas species were prevalent in clinical samples and environmental samples. Since the emergence of MAR Pseudomonas species is a public health issue, this work support the need for regular and consistent monitoring of municipal sewage effluents with a view to preventing the dissemination of these pathogens into the environment.

\section{References}

Alexopoulos, A., Plessas, S., Voidarou, C., Noussias, H., Stavropoulou, E., Mantzourani, I., Tzora, A., Skoufos, I. and Bezirtzoglou, E. (2011). Microbial ecology of fish species growing in Greek sea farms and their watery environment. Anaerobe. (A paper on the microbial ecology of fishes)

Brooks, G.F., Karen, C.C., Janet, S.B. and Stephen, A.M. (2011). Medical Microbiology. Jawetz, Melnick, \& Adelberg. 25th edition, McGraw-Hill LANG. Chapter 16.

Campisano, A., Overhage, J. and Rehm, B.H. (2008). The polyhydroxyalkanoate biosynthesis genes are differentially regulated in planktonic- and biofilm-grown Pseudomonas Biotechnology. 133: 442-452. aeruginosa. 
Iwane, T., Urase, T. and Yamamoto, K. (2001). Possible impact of treated wastewater discharge on incidence of antibiotic resistant bacteria in river water. Water Science Technology. 43: 9199.

Jalal, S. and Wretlind, B. (1998). Mechanisms of quinolone resistance in clinical strains of Pseudomonas aeruginosa. Microbiology Drug Resistance. 4: 257-261.

Magiorakos, A.P. (2011). Multidrug-Resistant (MDR), Extensively Drug Resistant (XDR) and Pandrug-1 Resistant (PDR) Bacteria in Healthcare Settings. Expert Proposal for a Standardized International Terminology.

Marufa, N., Animesh, S., Malek, M.A. and Ansaruzzaman, M.D. (2015). Prevalence and resistance pattern of Pseudomonas aeruginosa isolated from surface water. Advances in Microbiology. 5: 74-81.

Mavridou, A., Papapetropoulou, M., Boufa, P., Lambiri, M. and Papadakis, J.A. (1994). Microbiological quality of bottled water in Greece. Letters in Applied Microbiology. 19: 213-216.

Meenakumari, S., Verma, S,H., Absar, A. and Chaudhary, A. (2011). Antimicrobial susceptibility pattern of clinical isolates of Pseudomonas aeruginosa in an Indian cardiac hospital. International Journal Engineering Science and Technology 3:7117-7124.

Mena, K.D. and Gerba, C.P. (2009). Risk assessment of Pseudomonas aeruginosa in water. Reviews of Environmental Contamination and Toxicology 201: 71-115.

Murray, P.R., Rosenthal, K.S., Kobayashi, G.S. and Pfaller, M.A. (2002). Medical Microbiology. Fourth Edition. Philadelphia: Elsevier Mosby, pp. 278-303.

Navon-Venezia, S., Ben-Ami, R. and Carmeli, Y. (2005) Update on Pseudomonas aeruginosa and Acinetobacter baumannii infections in the healthcare setting. Current Opinion on Infectious Diseases. 18: 306-313.
Oduyebo O.O., Ogunsola, F.T. and Odugbemi, T. (1997). Prevalence of multi-resistant strains of P.aeruginosa isolated at the Lagos University Teaching Hospital from 1994- 1996. Nigeria Quarterly Journal of Medicine. 7: 373-376.

Okeke, I.N. and Sosa, A. (2003). Antibiotic resistance in Africa - Discerning the enemy and plotting a defence. African Health. 25(3); 1015.29

Olayinka, B.O., Olonitola, O.S. and Olayinka, A.T. and Agada, E. A. (2004). Antibiotic susceptibility pattern and multiple antibiotic resistance index of Pseudomonas aeruginosa urine isolates from a University Teaching Hospital. African Journal of Clinical and Experimental Microbiology. 5 (2): 198-202.

Olayinka, A.T., Onile, B.A. and Olayinka, B.O. (2009). Antibiotic susceptibility and plasmid pattern of Pseudomonas aeruginosa from the surgical unit of a university teaching hospital in north central Nigeria. Internal Journal of Medicine and Medical Sciences. 1(3): 079-083.

Pirnay J.-P., Matthijs S., Colak H., Chablain P., Biloca F., van Eldere J., de Vos D., Zizi M., Triest L. and Cornelis, P. (2005). Global Pseudomonas aeruginosa biodiversity as reflected in a Belgian river. Environmental Microbiology. 7:969-980.

Rossolini,G.A. and Mantengoli, E. (2005). Clinical Microbiology and Infection. Science Direct. 11: $17-32$

Schwartz, T., Kohnen, W., Jansen, B. and Obst, U. (2003). Detection of antibiotic-resistant bacteria and their resistance genes in wastewater, surface water, and drinking water biofilms. FEMS Microbiology Ecology. 43: 325335.

Silby, M.W., Winstanley, C., Godfrey, S.A.C., Levy, S.B. and Jackson, R.W. (2011). Pseudomonas genomes: diverse and adaptable, FEMS Microbiology Reviews. 35: $652-680$.

Todar, K. (2011). Pseudomonas species. Todar's online book of bacteriology. 